Published in final edited form as:

Curr Opin Psychiatry. 2008 September ; 21(5): 490-494. doi:10.1097/YCO.0b013e328308b2ee.

\title{
Adjudicative Competence
}

\author{
Sharron E. Dawes ${ }^{\mathrm{a}}$, Barton W. Palmer ${ }^{\mathrm{a}, \mathrm{b}}$, and Dilip V. Jeste $\mathrm{a,c}$ \\ aDepartment of Psychiatry, University of California, San Diego \\ bSan Diego Veterans Medical Research Foundation \\ cDeparment of Psychiatry, Veterans Affairs San Diego Healthcare System
}

\begin{abstract}
Purpose of review-Although the basic standards of adjudicative competence were specified by the U.S. Supreme Court in 1960, there remain a number of complex conceptual and practical issues in interpreting and applying these standards. In this report we provide a brief overview regarding the general concept of adjudicative competence and its assessment, as well as some highlights of recent empirical studies on this topic.
\end{abstract}

Findings-Most adjudicative competence assessments are conducted by psychiatrists or psychologists. There are no universal certification requirements, but some states are moving toward required certification of forensic expertise for those conducting such assessments. Recent data indicate inconsistencies in application of the existing standards even among forensic experts, but the recent publication of consensus guidelines may foster improvements in this arena. There are also ongoing efforts to develop and validate structured instruments to aid competency evaluations. Telemedicine-based competency interviews may facilitate evaluation by those with specific expertise for evaluation of complex cases. There is also interest in empirical development of educational methods to enhance adjudicative competence.

Summary-Adjudicative competence may be difficult to measure accurately, but the assessments and tools available are advancing. More research is needed on methods of enhancing decisional capacity among those with impaired competence.

\section{Keywords}

Competence; ethics; informed consent

\section{Introduction}

A task commonly faced by forensic psychologists, psychiatrists, and other mental health professionals working at the juncture between mental health and law is evaluating a defendant's capacity or competency to stand trial (adjudicative competence). Approximately $2 \%$ to $8 \%$ of all felony defendants are referred for evaluation of adjudicative competence; of these, approximately $10 \%$ to $30 \%$ are eventually deemed incompetent to stand trial $[1,2]$. In this article we provide a brief overview regarding the general concept of adjudicative competence and its assessment, as well as some highlights of recent empirical studies on this topic. Although our focus will be on adjudicative competence among adult defendants, those interested in the

Address correspondence to: Dilip V. Jeste, M.D., Ester and Edgar Levi Chair in Aging, Distinguished Professor of Psychiatry and Neurosciences, University of California, San Diego, Division of Geriatric Psychiatry, 116A-1, VA San Diego Healthcare System, 3350 La Jolla Village Drive, San Diego, CA 92161, Phone: (858) 534-4020, Fax: (858) 552-7404, E-mail: djeste@ucsd.edu. 
assessment of this construct among juvenile defendants are encouraged to refer to the recently published guide book by Grisso [3].

\section{What is Adjudicative Competence?}

The notion that a defendant should be mentally able to participate in the court proceedings has been present in the Western law in some form since the $14^{\text {th }}$ century C.E., at which time the English law required that the defendant be able to plea guilty or not guilty [4]. Within the contemporary American legal system, the present day application of the construct was largely defined in the landmark 1960 Supreme Court decision in Dusky vs. the U.S. 362 U.S. 402 (cited in Mossman et al. [5]). In that decision, the court determined that the key test of competency to stand trial is whether the defendant has "sufficient present ability to consult with his lawyer with a reasonable degree of rational understanding, and whether [he or she has] a rational as well as factual understanding of the proceedings against him " (quoted in Mossman et al.** [5], p. S5)

In a classic 1992 paper, Bonnie [6] proposed that adjudicative competence as defined by the Dusky criteria included only one of two relevant components. He suggested that the second, semi-separable component is decisional capacity, particularly as it relates to various decisions during the course of the trial that may affect a defendant's constitutional rights. Such decisional capacity would parallel that for other aspects, such as capacity to consent to (or refuse) treatment or to enroll in clinical research. The latter are generally construed in terms of the individual's capacity to understand the relevant information, to appreciate its significance for his or her situation or condition, and reason with that information (such as consider possible consequences of the various alternatives), as well as to express a clear choice [7,8]. Although Bonnie's model has been widely discussed, its legal status from subsequent case law remains murky [9]. In 1993 the Supreme Court rendered a decision in the case of Godinez v. Moran, which some have read as indicating that decisional capacity is not necessary, but others have interpreted it as indicating that decision making capacity is already inherent within the Dusky criteria $[2,10]$. Recently published guidelines from the American Academy of Psychiatry and the Law (AAPL) endorse the latter interpretation [11]. The preceding is just one many potential example of how the precise interpretation and application of the Dusky standards, and subsequent court decisions, as well as integration with state law, remain a complex endeavor [9].

\section{Who should conduct the assessments?}

Assessment of adjudicative competence is generally conducted by psychiatrists or psychologists [12-14]. A number of experts have raised concerns about the quality of competency evaluations by those without specialty training in forensic practice $[10,12,15]$. Although recent national summary data are unavailable, as of 1992, only $19 \%$ of the US states or territories required specific certification in forensic examination [14]. However, there do seem to be ongoing efforts within at least some of the individual states to add forensic board certification requirements [16].

As the qualifications and specific expertise of those conducting adjudicative competence evaluations receive increased scrutiny, there is likely to be an interest in obtaining opinions from the most seasoned experts available. Two recently published separate studies reported good correspondence in the results of adjudicative competence interviews conducted remotely, using video teleconferencing tools, with those conducted in person $[17,18]$. Clearly there will be many legal considerations in the application of such methods, and further research will be needed to delineate the actual viability and pitfalls of these methods for general forensic use. Nonetheless, this appears likely to be part of the general rise of interest in telemedicine and 
telepsychiatry to efficiently access the skills of interviewers with unique expertise regardless of geographic limitations.

\section{Reliability of Assessments}

The interrater reliability among forensic examiners in adjudicative competency opinions is unclear [19], but there does appear to be room for improvement even among the experts. As part of a recent survey study, Morris et al. [20] had board certified forensic psychiatrists or forensic psychologists respond to hypothetical vignettes. One of the two vignettes involved a patient who (per the authors) lacked rational understanding sufficient to assist in a rational defense due to specific fixed delusional beliefs, but who otherwise exhibited rational behavior and thinking. When asked to apply the Dusky "rational understanding" rule, $48 \%$ of the experts found the defendant competent, $52 \%$ found him incompetent to stand trail.

Although the vignette methodology of Morris et al'.s [20] study generated some debate in the form of letters to the editor [21-23], their finding of a near even-split among surveyed experts nonetheless raised concerns that there may be inconsistency and confusion about how the Dusky standards are routinely operationalized. The recent publication of specific and comprehensive guidelines for assessment of competency to stand trial by the APPL [11] may bring some clarity and consistency to the field. (These guidelines have already received several highly positive published reviews [11,24,25].

\section{Use of Structured Instruments}

One way to improve reliability is to use standardized methods. Efforts to develop structured assessments for adjudicative competence date back to at least 1965 when Robey [26] published the Criteria for Competency to Stand Trial checklist. In the subsequent 43 years a wide array of checklists and structured or semistructured interviews have been published for assessment of adjudicative competence. In a recently published practice survey of forensic psychologists, Archer et al. [27] found that the most frequently and widely used instrument for assessing adjudicative competence is the MacArthur Competence Assessment Tool - Criminal Adjudication (MacCAT-CA) [28]. But the MacCAT-CA is just one of several available instruments, all of which have their strengths and limitations. Detailed comparisons of these instruments are available in several excellent critical reviews [2,9,11,29], but the strengths and limitations of some of the most common instruments are listed in Table 1. It is important to keep in mind the that, as noted in the AAPL guidelines [11], "Designers of these instruments intend that they be used in concert with, rather than as a substitute for, a more comprehensive clinical examination" (p. S43).

\section{Adjudicative Competence Restoration}

If a defendant is deemed incompetent to stand trial, there may be efforts made to restore his or her capacity to a sufficient level to stand trial [38], e.g. by addressing any medical, substance abuse, or other neuropsychiatric conditions affecting mental status. Deficits in competency secondary to some conditions, such as some developmental disabilities, static deficits from a prior traumatic brain injury, or neurodegenerative conditions, may be difficult to resolve, but efforts are generally made to improve mental status among those deemed incompetent to stand trail due to acute exacerbations in psychiatric conditions such as psychosis. The latter raises the frequently discussed question of whether a defendant can be forced to take medication to improve his or her mental status, and thereby possibly enhance his or her competence to stand trial. This issue was addressed in the 2003 Supreme Court ruling on Sell vs. the U.S., wherein the court specified several conditions for the involuntary administration of medication. These included (1) How important the restoration is must be evaluated on a case-by-case basis, (2) That the medication must have minimal side-effects, (3) That there are no other options to 
restoration, and (4) That the medication is appropriate treatment for the disorder that caused the incompetence in the first place [38].

There has been a relative dearth of empirical research on psychoeducational interventions to enhance adjudicative competence. Mueller and Wylie [39] recently conducted a randomized comparison in inpatients (68\% of whom had a diagnosis of psychosis) who had been identified as incompetent to stand trial, that examined the effectiveness of a board-game-based educational program to teach patients about relevant legal concepts. The control condition involved a board game focused on teaching healthy behaviors. Both groups showed a pre- to post-intervention improvement on the MacCAT-CA understanding and appreciation scores, but there were no significant between-group differences. Although the findings did not support differential efficacy of this particular educational intervention, this study is of interest as a model for developing more effective non-pharmacologic methods of enhancing adjudicative competence. In other arenas of competence/decisional capacity, a number of studies have shown efficacy of enhanced educational methods [40-42].

\section{Discussion}

Adjudicative competence is a complex construct. Although empirical research on adjudicative competence is not a recent development (e.g., see the series of comprehensive reviews by Grisso and colleagues [43-45]), there remains room for empirical contributions to refining the construct and its assessment. Similar efforts and successes in the related arena of empirical bioethics [46-50], should encourage the ongoing efforts in the study of forensic competency issues as well.

\section{Acknowledgements}

This work was supported, in part, by the National Institute of Mental Health grants MH080002, MH019934, MH067902, MH064722 and National Institute on Aging grant AG28827 and by the Department of Veterans Affairs.

\section{Abbreviations}

APPl, American Academy of Psychiatry and the Law; MacCAT-CA, MacArthur Competence Assessment Tool-Criminal Adjudication.

\section{References}

* special interest

** outstanding interest

1. Roesch, R.; Zapf, PA.; Golding, SL., et al. Defining and assessing competency to stand trial. In: Hess, AK.; Weiner, IB., editors. The Handbook of Forensic Psychology. 2nd Edition. John Wiley \& Sons Inc.; Hoboken, NJ: 1999. p. 327-349.

2. Grisso, T. Evaluating Competencies: Forensic Assessments and Instruments. 2nd Edition. Kluwer Academic/Plenum Publishers; New York, NY: 2003.

3. Grisso, T. Evaluating Juveniles' Adjudicative Competence: A Guide For Clinical Practice. Professional Resource Press; Sarasota, FL: 2005.

4. Poythress, NG.; Bonnie, RJ.; Monahan, J., et al. Adjudicative Competence: The MacArthur Studies. Kluwer Academic/Plenum Publishers; New York, NY: 2002.

5. Mossman D, et al. AAPL practice guideline for the forensic psychiatric evaluation of competence to stand trial: an american legal perspective. J Am Acad Psychiatry Law 2007;35:S3-S72.This recently published document provides a thorough overview of the history and current status of law and empirical data related to adjudicative competence, and importantly, provides specific consensus guidelines for conducting such assessments. 
6. Bonnie RJ. The competence of criminal defendants: a theoretical reformulation. Behavl Sci Law 1992;10:291-316.

7. Appelbaum PS, Roth LH. Competency to consent to research: a psychiatric overview. Arch Gen Psychiatry 1982;39:951-958. [PubMed: 7103684]

8. Appelbaum PS, Grisso T. Assessing patient's capacities to consent to treatment. N Engl J Med 1988;319:1635-1638. [PubMed: 3200278]

9. Nussbaum DP, Hancock MB, Turner IBA, et al. Fitness/competency to stand trial: a conceptual overview, review of existing instruments, and cross-validation of the Nussbaum Fitness Questionnaire. Brief Treat Crisis Interven 2007;8:43-72.

10. Grisso T. Pretrial clinical evaluations in criminal cases: past trends and future directions. Crim Justice Behav 1996;23:90-106.

11. Fitch WL. AAPL practice guideline for the forensic psychiatric evaluation of competence to stand trial: an american legal perspective. J Am Acad Psychiatry Law 2007;35:509-513. [PubMed: 18086744]

12. Skeem JL, Golding SL. Community examiners' evaluations of competence to stand trial: common problems and suggestions for improvement. Profess Psychol Research Pract 1998;29:357-367.

13. Warren JI, Murrie DC, Stejskal W, et al. Opinion formation in evaluating the adjudicative competence and restorability of criminal defendants: a review of 8,000 evaluations. Behav Sci Law 2006;24:113132. [PubMed: 16557643]

14. Farkas GM, DeLeon PH, Newman R. Sanity examiner certification: an evolving national agenda. Prof Psychol Research Pract 1997;28:73-76.

15. Philipsborn, JT. Dealing With Experts on Competence to Stand Trial: Suggestions and Approaches - Part One. Champion (National Association of Defense Lawyers). 2008 [Accessed April 18, 2008]. Available via internet at: http://www.nacdl.org/public.nsf/ 01c1e7698280d20385256d0b00789923/1915890d8 8823b9985257410005105dd?OpenDocument

16. Moran M. In competency evaluations, training will matter. Psychiatr News 2007;42:26-55.

17. Lexcen FJ, Hawk GL, Herrick S, et al. Use of video conferencing for psychiatric and forensic evaluations. Psychiatr Serv 2006;57:713-715. [PubMed: 16675769]

18. Manguno-Mire GM, et al. The use of telemedicine to evaluate competency to stand trial: a preliminary randomized controlled study. J Am Acad Psychiatry Law 2007;35:481-489. [PubMed: 18086740] This study illustrated the potential viability of telepsychiatric methods for adjudicative competency assessment.

19. Missouri Institute of Mental Health, MIMH Policy Brief. Competency to Stand Trail. University of Missouri-Columbia; Columbia, MO: 2003.

20. Morris GH, Haroun AM, Naimark D. Assessing competency competently: toward a rational standard for competency-to-stand-trial assessments. J Am Acad Psychiatry Law 2004;32:231-245. [PubMed: 15515910]

21. Leong GB. Commentary: no rational reasons for changing competency-to-stand-trial standard. J Amer Acad Psychiatry Law 2004;32:246-249. [PubMed: 15515911]

22. Naimark D, Haroun A, Morris GH. "Assessing competency competently: toward a rational standard for competency-to-stand-trial assessments": Reply. J Am Acad Psychiatry Law 2005;33:134-135. [PubMed: 15809258]

23. Schacht TE. "Assessing competency competently: toward a rational standard for competency-tostand-trial assessments": Comment. J Am Acad Psychiatry Law 2005;33:134. [PubMed: 15809258]

24. Mackay RD. AAPL practice guideline for the forensic psychiatric evaluation of competence to stand trial: an English legal perspective. J Am Acad Psychiatry Law 2007;35:501-504. [PubMed: 18086742]

25. O' Shaughnessy RJ. AAPL practice guideline for the forensic psychiatric evaluation of competence to stand trial: a Canadian legal perspective. J Am Acad Psychiatry Law 2007;35:505-508. [PubMed: 18086743]

26. Robey A. Criteria for competency to stand trial: a checklist for psychiatrists. Am J Psychiatry 1965;122:616-623. [PubMed: 5843653]

27. Archer RP, Buffington-Vollum JK, Stredny RV, et al. A survey of psychological test use patterns among forensic psychologists. J Personality Assess 2006;87:84-94. 
28. Otto RK, Poythress NG, Nicholson RA, et al. Psychometric properties of the MacArthur Competence Assessment Tool-Criminal Adjudication. Psychol Assess 1998;10:435-443.

29. Rogers R, Grandjean N, Tillbrook CE, et al. Recent interview-based measures of competency to stand trial: A critical review augmented with research data. Behav Sci Law 2001;19:503-518. [PubMed: 11568958]

30. Lipsitt PD, Lelos D, McGarry AL. Competency for trial: a screening instrument. Am J Psychiatry 1971;128:105-109. [PubMed: 5170598]

31. Nicholson RA, Briggs SR, Robertson HC. Instruments for assessing competency to stand trial: how do they work? Prof Psychol Res Pract 1988;19:383-394.

32. Melton, GB.; Petrila, J.; Poythress, NG., et al. Psychological Evaluations for the Courts: A Handbook for Mental Health Professionals and Lawyers. 3rd Edition. Guilford Press; New York, NY: 2007.

33. Jacobs MS, Ryba NL, Zapf PA. Competence-related abilities and psychiatric symptoms: an analysis of the underlying structure and correlates of the MacCAT-CA and the BPRS. Law Hum Behav 2008;32:64-77. [PubMed: 17546483]

34. Pinals DA, Tillbrook CE, Mumley DL. Practical application of the MacArthur Competence Assessment Tool-Criminal Adjudication (MacCAT-CA) in a public sector forensic setting. J Am Acad Psychiatry Law 2006;34:179-188. [PubMed: 16844797]

35. Rogers, R.; Tillbrook, CE.; Sewell, KW. Evaluation of Competency to Stand Trial-Revised (ECSTR). Psychological Assessment Resources, Inc.; Odessa, FL: 2004.

36. Everington CT. The Competence Assessment for Standing Trial for Defendants with Mental Retardation (Cast-MR): A Validation Study. Crim Justice Behav 1990;17:147-168.

37. Everington C, Notario-Smull H, Horton ML. Can defendants with mental retardation successfully fake their performance on a test of competence to stand trial? Behav Sci Law 2007;25:545-560. [PubMed: 17486631]

38. Heilbrun K, Kramer GM. Involuntary medication, trial competence, and clinical dilemmas: implications of sell v. United States for psychological practice. Prof Psychol Res Pract 2005;36:459_ 466.

39. Mueller C, Wylie AM. Examining the effectiveness of an intervention designed for the restoration of competency to stand trial. Behav Sci Law 2007;25:891-900. [PubMed: 18046737]Although the findings were largely negative, this randomized controlled study is of interest as an initial attempt to empirically study nonpharmacologic interventions for enhancing adjudicative competence.

40. Eyler LT, Jeste DV. Enhancing the informed consent process: a conceptual overview. Behav Sci Law 2006;24:553-568. [PubMed: 16705663]

41. Jeste DV, et al. Multimedia consent for research in people with schizophrenia and normal subjects: a randomized controlled trial. Schiz Bull. 2008in pressThis study illustrated the effectiveness of multimedia tools for enhancing the decisional capacity.

42. Palmer BW, Cassidy EL, Dunn LB, et al. Effective use of consent forms and interactive questions in the consent process. IRB: Ethics \& Human Research 2008;30:8-12. [PubMed: 18512654]

43. Grisso T. Five-year research update (1986-1990): evaluations for competence to stand trial. Beh Sci Law 1992;10:353-369.

44. Cooper DK, Grisso T. Five year research update (1991-1995): evaluations for competence to stand trial. Behav Sci Law 1997;15:347-364. [PubMed: 9415961]

45. Mumley DL, Tillbrook CE, Grisso T. Five year research update (1996-2000): evaluations for competence to stand trial (adjudicative competence). Behav Sci Law 2003;21:329-350. [PubMed: 12808694]

46. Halpern SD. Towards evidence based bioethics. BMJ 2005;331:901-903. [PubMed: 16223827]

47. Kim SY. Evidence-based ethics for neurology and psychiatry research. NeuroRx 2004;1:372-377. [PubMed: 15717040]

48. Palmer BW, Savla GN. The association of specific neuropsychological deficits on capacity to consent to research or treatment. Journal of the International Neuropsychological Society 2007;13:10471059. [PubMed: 17942022]This comprehensive critical review revealed the importance of cognitive functions, more than psychopathologic symptoms, as predictors of decisional capacity. 
49. Palmer BW, Dunn LB, Appelbaum PS, Jeste DV. Correlates of treatment-related decision-making capacity among middle-aged and older patients with schizophrenia. Arch Gen Psychiatry 2004;61:230-236. [PubMed: 14993110]

50. Palmer BW, et al. Assessment of capacity to consent to research among older persons with schizophrenia, Alzheimer disease or diabetes mellitus: comparison of a three-item questionnaire with a comprehensive standardized capacity instrument. Arch Gen Psychiatry 2005;62:726-733.

[PubMed: 15997013] 
Table 1

Overview of Common Tests Used to Help Determine Adjudicative Competency

\begin{tabular}{|c|c|c|c|}
\hline Test & Description & Strengths & Weaknesses \\
\hline
\end{tabular}

\begin{tabular}{c|c|cc|c|c} 
Competency & \multicolumn{1}{|c|}{ Screening instrument } & Brief & High false positive eri
\end{tabular}

Screening Test

$[31]$

- 22 items

- $\quad$ standardized sentence completion task
- Good screen

- Good inter-rater reliability Good at prediction of competency rate

- Does not specifically address the Dusky criteria

\begin{tabular}{|l|l|l} 
& completion task & $\begin{array}{l}\text { Good inter-rater } \\
\text { reliability Good at } \\
\text { prediction of } \\
\text { competency }\end{array}$ \\
\hline
\end{tabular}

Georgia Court

Comp

Mississippi

State Hospital

[32]
- 21 questions

- Four areas: Understanding of courtroom procedure, Knowledge of the charge, Knowledge of possible penalties, and Ability to communicate rationally with an attorney.
- Good Screen

- Good inter-rater reliability
$1 / 3$ of questions based on a court-room layout that does not assess understanding, appreciation, or reasoning about the court procedures, and were of little use [33]
- Three subscales: (Reasoning abilities related to relevant and irrelevant material and pleading guilty or not-guilty, Understanding of the legal system and process, and Appreciation of the defendant's own situation)

- 22-item structured interview based on a vignette approach for Understanding and Reasoning (tailored for actua situation for Appreciation)

- $\quad$ Ages: 18 years and older
Competence

Tool - Crimina Adjudication

[29]

(18)

Fac

Factor structure was supported [34] in a sample of 177 participants who had been evaluated for competency

- Test was well normed (normative sample $=729$ individuals in a multisite study) [35].

- Good psychometric properties [35].

- Worked well with paranoid individuals and less

sophisticated

defendants who were attempting to

malinger [35].

Evaluation of

Competency to

Stand Trial -

Revised [36]

Assessment to

Stand Trial For

Defendants

With Mental

Retardation

[37]
- Semi-structured interview

- Three main areas covered are Factual Understanding of the courtroom proceedings,

Rational understanding of the courtroom proceedings, and Consultation with counsel.

- 18 Items

- $\quad$ Ages: 18 years and older
- Has good psychometric properties

- $\quad$ Specifically designed to correspond with the Dusky criteria.

- Screens for malingering

- Focuses on casespecific information including relationship with counsel

- $\quad$ Standardized

- $\quad$ Based on Dusky principles

- Good reliability egal concepts, Skills to assis defense, and Understanding of case events.

- 50 items
- Low false positive rates.
- Failure to detect specific delusional beliefs that might be detrimental to the defendant [35].

- Malingerers were often misidentified [35].

- Those with cognitive difficulties may become confused, and fail the MacCAT-CA due to memory and attention problems [35].

- Biased against people from certain cultural backgrounds who did no understand the vignettes [35].
As noted by Melton [33] some aspects of the scoring led can lead to substantial incongruity between item scores and overall interpretation of the scale results. 


\begin{tabular}{|c|c|c|c|}
\hline Test & Description & Strengths & Weaknesses \\
\hline & $\begin{array}{l}\text { - } \\
\text { - } \\
\text { Ages: Adults \& Adolescents } \\
\text { Time } 340 \text { minutes }\end{array}$ & & $\begin{array}{ll} & \text { Persons with mental } \\
\text { retardation able to } \\
\text { malinger successfully if } \\
\text { instructed to do so [38]. }\end{array}$ \\
\hline
\end{tabular}

